\title{
Detection of Coxiella burnetti Antibodies among Workers and Butchers at Dhamar Slaughter House, Yemen
}

\author{
Badi A. Fateh ${ }^{1}$, Hameed Ahmed Golah ${ }^{1}$, Ahmed Y. Al-Qudari ${ }^{1,2}$, \\ Maged Ahmed AL-Garadi ${ }^{1}$ and H.A Alhothy ${ }^{1}$ \\ ${ }^{1}$ Department of Veterinary Medicine ${ }^{-}$Faculty of Agriculture \& Veterinary Medicine, \\ Thamar University, Dhamar, Yemen \\ ${ }^{2}$ Department of Medical Laboratory Sciences, Faculty of Medical Sciences, \\ Al-Saeeda University, Dhamar, Yemen \\ *Corresponding author
}

\begin{tabular}{|c|c|}
\hline & A B S T R A C T \\
\hline $\begin{array}{l}\text { Coxiella burnetti, } \\
\text { Butchers, } \\
\text { Slaughter house, } \\
\text { Immunoblot }\end{array}$ & \multirow{3}{*}{$\begin{array}{l}\text { The Q-fever considered as occupational disease of persons dealing with livestock and their } \\
\text { products, although, almost no data have been identified on the situation of this disease in } \\
\text { Yemen, where } 70 \% \text { of their population depending on agriculture and raising animals. An } \\
\text { investigation for detection of antibodies against Coxiella burnetti in serum samples } \\
\text { collected from about } 50 \text { veterinarian and butchers who worked in Dharma's } \\
\text { slaughterhouse carried out using commercial immunoblot test. Of } 50 \text { sample examined, } \\
\text { three samples were positive (6\%), one sample was Phase-1 positive, six samples were } \\
\text { equivocal. The presence of Coxiella burnetti antibodies in processing Slaughter's house } \\
\text { workers may give in part preliminary indication of distribution of this disease in livestock } \\
\text { raising community and the necessity of enactment of publicly and occupational actions, } \\
\text { measures the limit, and prevent the devastating effects of this zoonotic disease on human } \\
\text { and animals. }\end{array}$} \\
\hline Article Info & \\
\hline $\begin{array}{l}\text { Accepted: } \\
\text { 04 February } 2019 \\
\text { Available Online: } \\
10 \text { March } 2019\end{array}$ & \\
\hline
\end{tabular}

\section{Introduction}

Q fever/ Query fever/ Balkan influenza/ abattoir fever was first described in Queensland, Australia, during an outbreak of a febrile illness of unknown origin among abattoir workers (Shakespeare, 2009). It's ubiquitous zoonotic disease caused by an extremely resistant intracellular bacterium, Coxiella burnetti (Anderson et al., 2013). This disease cause severe economic losses and can be considered severe public health problem in certain areas (Porter et al., 2011).
This may attributed in part to the fact that the disease has long been considered an underreported and underdiagnosed illness because symptoms frequently are nonspecific, making diagnosis challenging (Anderson et al., 2013). Further, Q fever is widespread in domestic ruminants and its sero-prevalence thought to have increased in recent often neglected in the differential diagnosis. The domestic ruminants represent the main source of infection and considered the main reservoir for pathogen that infect wide variety of hosts, mammals (humans, ruminants, small rodents, 
dogs, cats), birds, fish, reptiles and arthropod (Porter et al., 2011). Transmission of disease is by direct contact with contaminated materials, especially the afterbirth or material contaminated with amniotic fluid. There is some evidence that inhalation of dust from infected straw or bedding and even soil may also cause infection. Contaminated milk or milk products are also a possible route of infection, and transmission via ticks, lice or fleas has been demonstrated (Shakespeare, 2009).

The people at highest risk are abattoir workers, veterinarians, individuals working with hides, fleece or bones of infected animals. As result of that the disease considered as occupational zoonosis of agricultural and other workers closely involved with cattle and sheep (Shakespeare, 2009). The acute form of disease characterized by incubation period last a few days to several weeks, with less than $1 \%$ of fatalities. The main manifestation includes fever, severe headache, and chills are the symptoms most commonly seen. Fever usually peaks at $40^{\circ} \mathrm{C}$ and lasts approximately days. Fatigue and sweats also frequently found. Cough, nausea, vomiting, myalgia, arthralgia, chest pain, hepatitis, and occasionally, splenomegaly, osteomyelitis, and meningoencephalitis are also associated with acute $Q$ fever. In chronic $Q$ fever the endocarditis, primarily of the aortic and mitral valves, are the most common manifestation of chronic Q fever; although chronic hepatitis and infection of surgical lesions have been seen. Approximately $90 \%$ of Q fever endocarditis patients have preexisting valvular heart disease (Waag and Fritz, 2012).

The clinical manifestation of disease in animals, include stillbirth, delivery of weak lambs, calves, or kids, are the most frequent clinical signs of the disease. The abortion occurs at the end of gestation without specific clinical signs and pathognomic pathological findings, the intercotyledonary fibrous thickening and discolored exudates, may observed (Shakespeare, 2009). There are different serological tests available for $\mathrm{Q}$ fever, including Indirect Fluorescent Antibody Tests (IFAT), Enzyme linked Immunosorbent Assays (ELISA) and Complement Fixation Tests (CFT) (WegdamBlans et al., 2012).

\section{Materials and Methods}

\section{Study area and samples collection}

This study was conducted at Slaughterhouse of Dhamar governorate. Uncoagulated blood samples collected from 50 veterinarian and butchers who worked in Dhamar city slaughter house. The samples collected from appropriate vein under aseptic manner in Plain blood collection tubes. The blood samples transported in icebox into laboratory, Faculty of Agriculture \&Veterinary Medicine.

\section{Samples preparation}

The serum separated from blood by incubation the tubes in an upright position at room temperature for 30 minutes and then centrifuged at $1200 \mathrm{~g}$ for 10 minutes. The serum samples aspirated into Eppendorf 1.5 tubes labeled and stored at -20 until Q- fever testing.

\section{Immuno DOT assay}

The ImmunoDOT assay, utilizing an enzymelinked immunoassay (EIA) dot technique for the detection of $\operatorname{IgG}$ and $\operatorname{IgM}$ antibodies to $C$. burnetti (GENBIO, San Diego, CA, USA). The Immuno DOT test procedure and results interpretation performed according to the procedure of Manufacturer's instructions. The aluminum blocks (GENBIO, San Diego, CA, USA) and water bath (Memmert, Germany) 
protocol applied to performing the test procedures in the required optimal temperature. Briefly, the kit left in room temperature for about 30 minutes. Four reaction vessels (cuvette) per serum samples inserted into appropriate slots in aluminum blocks, which in turn placed in water bath. $2 \mathrm{~mL}$ of diluent, enhancer, conjugate and developer were placed into their corresponding vessel (1), (2), (3) and (4), and the thermometer used for calibrating the temperature inside the vessels to $48{ }^{\circ} \mathrm{C}$. After adjusting the temperature in the vessels (10 minutes waiting), ten microliter of each serum sample were pipetted into reaction vessels 1 and then demonized water wetted strips were, inserted into the that vessels, moved up and down for about 10 seconds, and stood in vessels (1) for 15 minutes. The strips then washed with deionized water (Clarifier), by swishing the entire strip windows by swift back and forth motion for about 10 seconds. The same steps repeated for each strip with remaining vessels but with different incubation time, which was 5 minutes in vessels (2), 15 minutes in vessels (3), 5 minutes in clarifier, and 5 minutes in vessels (4). The strips wetted by slight pressing against filter paper. To ensure the good quality of test procedure, only strips with clear blue dot in positive control window and without dot in negative control widow considered. The strips with clear blue dot in four test windows (Phase 1, Phase 2 dilution 3 , Phase 2 dilution 2 and Phase 2 dilution 1) were considered as positive, If strips with only Phase 1 positive the results were interpreted as phase 1 positive (only if associated with consistent symptomatology that indicated chronic infection).

\section{Results and Discussion}

The results of this study shows that the presence of antibodies against Coxiella burnetti in serums from workers and veterinarian of Dhamar slaughter house. Only three positive serum samples (one for veterinarian and tow for butchers) that were reactive to Coxiella burnetti antigens (Phase-I and II) in all the windows of kit strip. The samples that show reaction to strip window containing Coxiella burnetti Phase-I antigen were three of which one were accompanied with clinical signs claim so it was reported as Phase-I antigen positive, the two other samples reported as equivocal. Other samples were negative or weakly reactive (4 samples) which show reaction with Phase-II antigen dilution-1 as showed in table 1 .

Table.1 Percentages of Positive, Phase 1 positive and suspected Q-fever slaughterhouses' workers

\begin{tabular}{|c|c|c|c|c|}
\hline \multicolumn{1}{|c|}{ Categories } & Positive & Phase-I Positive & Equivocal & Negative \\
\hline Veterinarian & 1 & 1 & 3 & 1 \\
\hline \multicolumn{1}{|c|}{ Butchers } & $2^{*}$ & - & 3 & 39 \\
\hline Total & 3 & 1 & 6 & 40 \\
\hline$\%$ & 6 & 2 & 12 & 80 \\
\hline $\begin{array}{l}\text { Result } \\
\text { interpretation } \\
\text { according to } \\
\text { manufacture }\end{array}$ & $\begin{array}{c}\text { Reported as } \\
\text { "positive" } \\
\text { when Phase-I } \\
\text { and Phase-II dots } \\
\text { were } \\
\text { Positive }\end{array}$ & $\begin{array}{c}\text { Reported as } \\
\text { "Phase-1 } \\
\text { Positive" } \\
\text { when } \\
\text { accompanied } \\
\text { with clinical } \\
\text { signs }\end{array}$ & $\begin{array}{c}\text { Reported as } \\
\text { "equivocal" } \\
\text { when there were } \\
\text { no claims of } \\
\text { clinical } \\
\text { signs }\end{array}$ & $\begin{array}{c}\text { Reported as } \\
\text { "Negative" }\end{array}$ \\
$\begin{array}{c}\text { When no reactions } \\
\text { were recorded in } \\
\text { all windows } \\
\text { of test strip }\end{array}$ \\
\hline
\end{tabular}

* No claims for the preexisting clinical signs 
The results of this study showed that the antibodies against $C$. burnetti in some veterinarian and butchers who works in Dhamar city Slaughterhouse were present. The presence of Q-fever antibodies in occupational highly risk people have been confirmed by many studies (Wilson et al., 2010; Wade et al., 2006; Brouqui et al., 2004; McQuiston and Childs, 2002; Carrieri et al., 2002; Cracea, 1987; CDC, 1986; Haas and Hacks, 1971; Topping et al., 1947; Irons et al., 1947; Irons and Hooper, 1947; Cox et al., 1947).

The occupation and the duration of exposure to infectious agent affect the persistence of antibodies in blood and exacerbate the devastating effects of the disease (Nakladalova et al., 2014). The results of this study indicated that the Slaughterhouse workers have been previously exposure to the $C$. burnetti most possibly from the slaughtered animals. These may imply that the workers exposed to causative agent mostly from the reservoir host (cattle, sheep, and goats) which brought into slaughterhouse. The slaughtered animals are mostly local breeds belonging to, whether farmers reside in city or villagers neighbouring the city or butchers, who bought local and imported breeds of animals and residing them in the city.

The presence of antibodies against like occupational disease, in highly risk people it may be guided to imagine, the extent to which this air-born disease may distribute in community and the size of unrealizable problems. Further studies, using doubtless diagnostic test, should intended to determine the epidemiological situation of Q-fever in both human and animals and then the suitable measure could take. This may supported by the study that indicated the detection of Qfever in hepatitis suffered people reside in rural areas of Yemen (Gray et al., 1999).

\section{Acknowledgment}

This research partially supported by grants in aid from Relief international, we are grateful to the Dhamar slaughterhouse administration, workers and veterinarians for their help in carrying out this study. We wish to thank Mr. Fred alder (GenBio Company, USA) for providing the discount of ImmunoDot kits and aluminum blocks.

\section{References}

Anderson, A., Emerging, N. C. F., Diseases, Z. I. D. D. O. V.-B. and GROUP, Q. F. W. 2013. Diagnosis and Management of $Q$ Fever -- United States, 2013: Recommendations from $C D C$ and the $Q$ Fever Working Group, U.S. Department of Health and Human Services, Public Health Service, Centers for Disease Control and Prevention.

Brouqui, P., Badiaga, S. and Raoult, D. 2004. Q fever outbreak in homeless shelter. Emerg Infect Dis, 10, 1297-9.

Carrieri, M. P., Tissot-Dupont, H., Rey, D., Brousse, P., Renard, H., Obadia, Y. and Raoult, D. 2002. Investigation of a slaughterhouse-related outbreak of $\mathrm{Q}$ fever in the French Alps. Eur J Clin Microbiol Infect Dis, 21, 17-21.

CDC 1986. Q fever among slaughterhouse workers--California. MMWR. Morbidity and mortality weekly report, 35, 223.

Cox, H. R., Tesar, W. C. and Irons, J. V. 1947. Q fever in the United States; isolation and identification of rickettsias in an outbreak among stock handlers and slaughterhouse workers. J Am Med Assoc, 133, 820.

Cracea, E. 1987. Q fever epidemiology in Roumania. Zentralbl Bakteriol Mikrobiol Hyg A, 267, 7-9.

Gray, G. C., Kassira, E. N., Rodier, G. R., 
Myers, M. C., Calamaio, C. A., Gregory, M., Nagi, M. A., Kamal, K., Botros, B. A., Soliman, A. K., Hassan, N. F., Gregory, R., Arunkumar, B. K., Cope, A. and Hyams, K. C. 1999. Remote village survey for agents causing hepatosplenic disease in the Republic of Yemen. Trop Doct, 29, 212-9.

Haas, J. and Hacks, W. H. 1971. [Observations during the 1966 Q fever epidemic in the Hamburg slaughterhouse]. Med Klin, 66, 391-5.

Irons, J. V. and Hooper, J. M. 1947. Q fever in the United States; clinical data on an outbreak among stock handlers and slaughterhouse workers. J Am Med Assoc, 133, 815-8.

Irons, J. V., Murphy, J. N. and Wolfe, D. M. 1947. Q fever in the United States; serologic observations in an outbreak among stock handlers and slaughterhouse workers. J Am Med Assoc, 133, 819.

Mcquiston, J. H. and Childs, J. E. 2002. Q fever in humans and animals in the United States. Vector Borne Zoonotic Dis, 2, 179-91.

Nakladalova, M., Pastorkova, R. and Landecka, I. 2014. [Q fever - an occupational disease leading to disability - case report]. Epidemiol Mikrobiol Imunol, 63, 149-52.

Porter, S. R., Czaplicki, G., Mainil, J., Guatteo, R. and Saegerman, C. 2011. Q Fever: current state of knowledge and perspectives of research of a neglected zoonosis. International journal of microbiology, 2011.

Shakespeare, M. 2009. Zoonoses [electronic resource], Pharmaceutical Press.

Topping, N. H., Shepard, C. C. and Irons, J. V. 1947. Q fever in the United States; epidemiologic studies of an outbreak among stock handlers and slaughterhouse workers. J Am Med Assoc, 133, 813-5.

Waag, D. M. and Fritz, D. L. 2012. 10 Q fever. Biodefense Research Methodology and Animal Models, 179.

Wade, A. J., Cheng, A. C., Athan, E., Molloy, J. L., Harris, O. C., Stenos, J. and Hughes, A. J. 2006. Q fever outbreak at a cosmetics supply factory. Clin Infect Dis, 42, e50-2.

Wegdam-Blans, M., Wielders, C., Meekelenkamp, J., Korbeeck, J., Herremans, T., Tjhie, H., Bijlmer, H., Koopmans, M. and Schneeberger, P. 2012. Evaluation of commonly used serological tests for detection of Coxiella burnetii antibodies in welldefined acute and follow up sera. Clinical and Vaccine Immunology, 19, 1110-1115.

Wilson, L. E., Couper, S., Prempeh, H., Young, D., Pollock, K. G., Stewart, W. C., Browning, L. M. and Donaghy, M. 2010. Investigation of a $Q$ fever outbreak in a Scottish co-located slaughterhouse and cutting plant. Zoonoses Public Health, 57, 493-8.

\section{How to cite this article:}

Badi A. Fateh, Hameed Ahmed Golah, Ahmed Y. Al-Qudari, Maged Ahmed AL-Garadi and Alhothy, H.A. 2019. Detection of Coxiella burnetti Antibodies among Workers and Butchers at Dhamar Slaughter House, Yemen. Int.J.Curr.Microbiol.App.Sci. 8(03): 361-365. doi: https://doi.org/10.20546/ijcmas.2019.803.045 